\title{
An Application of Artificial Neural Network for Predicting Engine Torque in a Biodiesel Engine
}

\author{
Bekir Cirak*, Selman Demirtas \\ Siirt University, Faculty of Engineering \&Architecture, Department of Mechanical Engineering, Kezer Campus, Siirt / TURKEY \\ *Corresponding author: bekircirak@mynet.com
}

Received June 09, 2014; Revised August 02, 2014; Accepted August 12, 2014

\begin{abstract}
In this application study, an artificial neural network (ANN) model to predict the torque of a diesel engine. Using ANN performance of a diesel engine using biodiesel produced from canola and soybean oils through transesterification. To acquire data for training and testing of the proposed ANN. A four cylinder and four stroke test engine was fuelled with biodiesel and eurodiesel mixtured fuels with various percentages of biodiesel \% amounts to half the CB with SB and operated at different loads engine speeds, coolant temperatures, biofuel mixtures and exhaust temperature. Levenberg Marquards algorithms for the engine was developed using some of the experimental data for training. As a nonlinear system has been accepted. The performance of the ANN was validated by comparing the prediction dataset with the experimental results. It was observed that the ANN model can predict the engine performance quite well with correlation coefficient R 0.98 for the engine torque respectively. The prediction MSE (Mean Square Error) error was between the desired outputs as measured values and the simulated values were obtained as 0.0002 by the model.
\end{abstract}

Keywords: biofuel, coolant temperature, engine torque, Levenberg Marquardt, ANN

Cite This Article: Bekir Cirak, and Selman Demirtas, “An Application of Artificial Neural Network for Predicting Engine Torque in a Biodiesel Engine.” American Journal of Energy Research, vol. 2, no. 4 (2014): 7480. doi: 10.12691/ajer-2-4-1.

\section{Introduction}

At the present time, exhaust emissions released by vehicles show an increase together with the increase in the number of vehicles [1]. The use of fuels obtained from vegetable products in internal combustion engines as renewable energy is not a new issue in fact studies have been conducted on a global scale for a long time [2]. An engineering concept may infix sophisticated physical, chemical or electrical theory and may require very complicated arithmetic to describe them. Arithmetic emerged may not be solvable in closed form. While energy efficiency is an important issue the development and encouragement of technologies that will use renewable energy sources and extending the use of such technologies constitutes another important step in national energy studies [3].

Biodiesel has certain advantages such that it can be used as fuel in diesel-engine vehicles without requiring much modification on the engine, can be produced from local sources, is a renewable fuel and has good burning characteristics owing to its oxygen content [4]. Due to these advantages biodiesel has emerged as an alternative fuel studies on which have been carried out in recent years [5]. Biodiesel does not contain petroleum but it can be used as fuel in pure form or mixed with petroleum based diesel fuel at any ratio [6]. The effect of biodiesel as fuel for diesel engine has become a craze due to the depleting petroleum resources. For commercial implementation of this as an alternative fuel for engine, its performance analysis has become a necessity for optimization of the best acceptable biodiesel and commercial diesel mixture. However, the experimental investigation of the performance of an engine is complex, time consuming, and costly, especially for studies involving usage of many different mixtures [7]. In the existing literatures was shown that the use of ANN is a powerful modeling tool that has the ability to identify complex relationships from input and output data. Therefore the objective of this study is to develop a neural network model for predicting for the engine torque of the engine in relation to input variables including engine speed, biofuel mixtures, exhaust temperature and coolant temperature. This model is of a great significance due to its ability to predict engine performance under varying conditions [8]. Kalogirou reviewed artificial intelligence for the modeling and control of combustion processes [9]. Sayin et al. investigated the performance and exhaust emissions of a gasoline engine using ANN [10].

The effects of valve-timing in a spark ignition engine on the engine performance and fuel economy was studied by Golcu et al. [11]. Yuanwang et al. observed the effect of cetane number on exhaust emissions from engine [12]. Ghobadian et al. have investigated combustion analysis of internal combustion engines performance using biofuels with an artificial neural network [13]. Some researchers studied ANNs method to predict internal combustion engine characteristics. Parlak et al. used ANNs to predict 
specific fuel consumption and exhaust temperature for a diesel engine [14].The progress of neurobiology has allowed researchers to build mathematical models of neurons to simulate neural behavior. Artificial neural networks (ANNs) are used to solve a wide variety of problems in science and engineering, particularly for some areas where the conventional modeling methods fail. A well trained ANN can be used as a predictive model for a specific application which is a data processing system inspired by biological neural system. The predictive ability of an ANN results from the training on experimental data and then validation by independent data. An ANN has the ability to relearn and adapt for improving its performance with the availability of updated data [15].

\section{Experimental Results}

In this study biodiesel was produced from soybean and canola oils through transesterification. The biodiesel fuels produced in the study were used for preparing 4\% biodiesel, 96\% eurodiesel and 8\% biodiesel, 92\% eurodiesel fuel mixtures and these mixtures were tried out in a diesel engine. The experiments were conducted at
Sakarya University Faculty of Central Laboratory. In the study a test apparatus which consisted of a diesel engine and a dynamometer device was constructed in order to compare canola oil methyl ester and soybean oil methyl ester with Eurodiesel fuel. A Citroen mark four cylinder, four cycle and water cooled diesel engine with a pump injector fuel system was used in the experiments. The technical characteristics of the engine are given in Table 1.

Table 1. Test engine specification

\begin{tabular}{ll}
\hline Engine mark & General \\
\hline Engine stroke & 4 \\
\hline Engine volume & $1422 \mathrm{cc}$ \\
\hline Cylinder number & 4 \\
\hline Cylinder diameter & $79.50 \mathrm{~mm}$ \\
\hline Fuel system & Pump injector \\
\hline Fuel Type & Diesel \\
\hline Compression ratio & $19.5: 1$ \\
\hline Maximum prower & $72 \mathrm{~kW}$ at $5000 \mathrm{~d} / \mathrm{d}$ \\
\hline Maximum Torque & $165 \mathrm{Nm}$ at $1600 \mathrm{~d} / \mathrm{d}$ \\
\hline
\end{tabular}

A Biodiesel fuels that were produced from canola oil methyl ester and soybean oil methyl ester and Eurodiesel fuel were used in the experiments. Figure 1 shows Experimental setup and test engine used in the study.

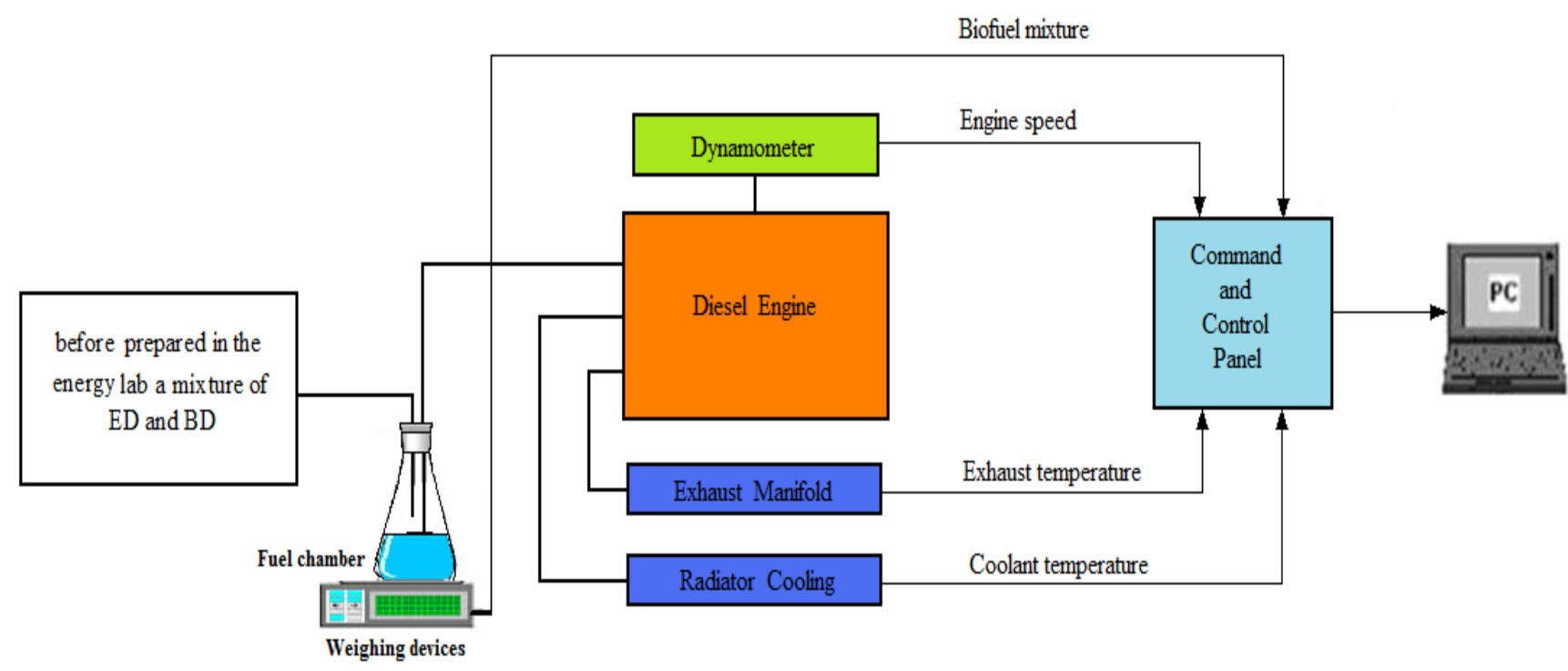

Figure 1. Experimental setup and test engine

Exhaust manifold connections of the dynamometer and radiator cooling connections were checked before starting the experiments. The engine was started and operated for approximately five minutes until it warmed up. The measurements started after the engine reached the operating coolant temperature. Following the finish of the test with each fuel, the engine was stopped to be reverted back to the conditions before the test. The pipes in the fuel system of the engine and the fuel filter were emptied. Afterwards the new fuel was filled in the fuel tank. After the engine warmed up, the gas lever was switched to full throttle and the engine was operated at full load.

The engine that was under full load was operated at 1500 1/min, 2000 1/min, $25001 / \mathrm{min}, 30001 / \mathrm{min}, 3500$ $1 / \mathrm{min}, 40001 / \mathrm{min}$ respectively with the help of the load control lever on the operation panel of the coolant temperature, exhaust temperature and engine speed the data required for the engine performance characteristics were obtained. All the tests were conducted in the same environment and under the same conditions. Table 2 shows data values of input and output in experiments. This datas used in ANN train and test. The values recorded in the system and the process is running this operation panel. A total of 60 samples were taken from the value. Biofuel mixture of up to $20 \%$ rate in parameter values have been accepted. This study used a mixture of BD 20\% max. Other rate is \% 80 ED. Half of the amount of each BD\% SB formed from the other half of the CB.

This model is of a great importance due to its ability to predict engine performance under varying conditions. The experimental data set consist of 60 samples of which 30 dataset were used for training the network, 5 dataset were used for validating the network and 6 dataset were chosen randomly for testing the performance of the trained network. After the network has successfully completed the training stage, it was tested with the experimental data which were not present in the training data set. 
Table 2. Sample data values

\begin{tabular}{|c|c|c|c|c|c|}
\hline Data No & Exahaust Temperature $\left({ }^{\circ} \mathrm{C}\right)$ & Coolant Temperature $\left({ }^{\circ} \mathrm{C}\right)$ & Engine Speed (rpm) & Biofuel Mixture (\%) & Engine Torque (Nm) \\
\hline 1 & 200 & 5 & 500 & 2 & 70 \\
\hline 2 & 250 & 10 & 1000 & 4 & 75 \\
\hline 3 & 300 & 15 & 1500 & 6 & 80 \\
\hline 4 & 350 & 20 & 2000 & 8 & 85 \\
\hline 5 & 400 & 25 & 2500 & 10 & 90 \\
\hline 6 & 450 & 30 & 3000 & 12 & 95 \\
\hline 7 & 400 & 35 & 3500 & 14 & 100 \\
\hline 8 & 300 & 40 & 4000 & 16 & 105 \\
\hline 9 & 450 & 45 & 1500 & 18 & 110 \\
\hline 10 & 400 & 50 & 2000 & 20 & 115 \\
\hline 11 & 300 & 55 & 1500 & 6 & 70 \\
\hline 12 & 250 & 60 & 2000 & 8 & 80 \\
\hline 13 & 400 & 65 & 2500 & 10 & 75 \\
\hline 14 & 350 & 70 & 3000 & 2 & 85 \\
\hline 15 & 400 & 75 & 3000 & 6 & 95 \\
\hline 16 & 350 & 80 & 2500 & 12 & 100 \\
\hline 17 & 300 & 85 & 3000 & 14 & 110 \\
\hline 18 & 400 & 90 & 3500 & 16 & 115 \\
\hline-- & -- & -- & -- & -- & -- \\
\hline-- & -- & -- & -- & -- & -- \\
\hline 55 & 450 & 25 & 1500 & 12 & 80 \\
\hline 56 & 400 & 30 & 2000 & 14 & 75 \\
\hline 57 & 300 & 35 & 1500 & 16 & 85 \\
\hline 58 & 200 & 60 & 3000 & 6 & 70 \\
\hline 59 & 250 & 65 & 3500 & 8 & 75 \\
\hline 60 & 300 & 70 & 4000 & 10 & 80 \\
\hline
\end{tabular}

\subsection{ANNs Structure}

Artificial neural networks (ANNs) are a structure consisting of a large number of very simple units which combine to represent any given relationship of inputs and outputs. The name originates from the biological structures which inspired them. ANNs are used to solve a wide variety of problems in science and engineering, particularly for some areas where the conventional modeling methods fail. A well trained ANNs can be used as a predictive model for solving of specific problems, which is a data processing system inspired by biological neural system. The predictive ability of ANNs results from the training on experimental data and then validation by independent data. An ANN has the ability to re learn to improve its performance if new available data [16]. A neural network is composed of large numbers of highly interconnected processing elements known as neurons. The basic elementsof an artificial neuron are shown in Figure 2. Artificial neuron consists of weight bias and activation function mainly. Each neuron receives inputs $x_{1}$, $x_{2}, \ldots, x_{n}$ attached with a weight $x_{i}$ which shows the connection strength for a particular input for each connection [17].

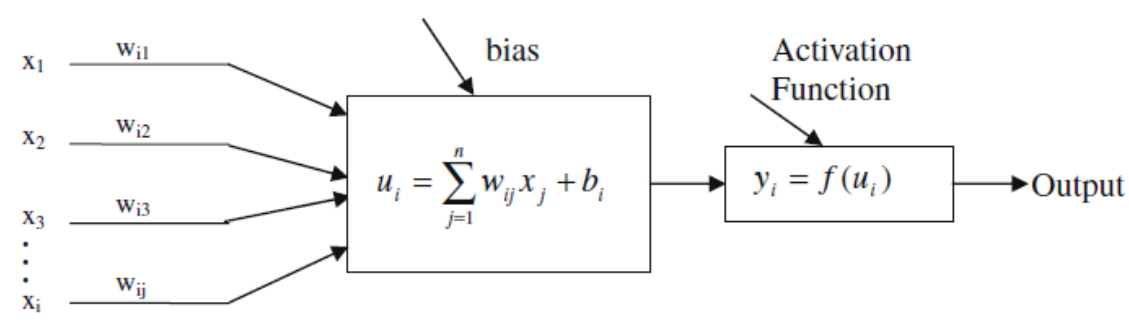

Figure 2. The style of neural computation

Every input is then multiplied by the corresponding weight of the neuron connection. A bias $b_{i}$ can be defined as a type of connection weight with a constant non zero value added to the summation of inputs and corresponding weights $u$ given as follows:

$$
u_{i}=\sum_{j=1}^{n} w_{i j} x_{j}+b_{i}
$$

The summation $u_{i}$ is transferred using a scalar to scalar function called an activation or transfer function $f\left(u_{i}\right)$ to yield a value called the unit's activation given as

$$
y_{i}=f\left(u_{i}\right)
$$

Activation functions serve to introduce nonlinearity into neural networks which makes it more powerful than linear transformation. Levenberg marquardt algorithm which is the most widely used training algorithm for the multi layer perception is a gradient descent technique to minimize the error for a particular training pattern [18]. Accordingly for a given input pattern a flow of activation is forwarded from the input layer to the output layer via hidden layer(s). Then the errors in the output are initiated. LMA is used to adjust the weights a small amount at a time in away that 
reduces the error. The training of the network is accomplished by adjusting the weights and is carried out through a large number of training sets and training cycles (epochs). The goal of the learning procedure is to find the optimal set of weights which in the ideal case would produce the right output for any input. The output of the network is compared with a desired response to produce an error. Once the ANN is adequately trained. it can generalize to similar cases which it has never seen. Detailed information about ANN and its working principles can be found in ref [19].

The ANNs usually consist of an input layer, some hidden layers and an output layer. In its simple form each single neuron is connected to other neurons of a previous layer through adaptable synaptic weights. Data is usually stored as a set of connection weights. Training is the process of modifying the connection weights, in some orderly fashion using a suitable learning method. The ANNs uses a learning model in which an input is presented to the network along with the desired output and the weights are adjusted so that the network attempts to produce the desired output. The weights after training contain meaningful information whereas before training they are random and have no meaning [20]. Multilayer perceptrons are the best known and most widely used kind of ANNs. Networks with interconnections that do not form any loops are called feedforward. Recurrent or non feedforward networks in which there are one or more loops of interconnections are used for some kinds of applications [21]. Figure 3 shows the architecture of a general three layered feedforward neural network model. The neural network considered is fully connected in the sense that every unit belonging to each layer is connected to every unit belonging to the adjacent layer.

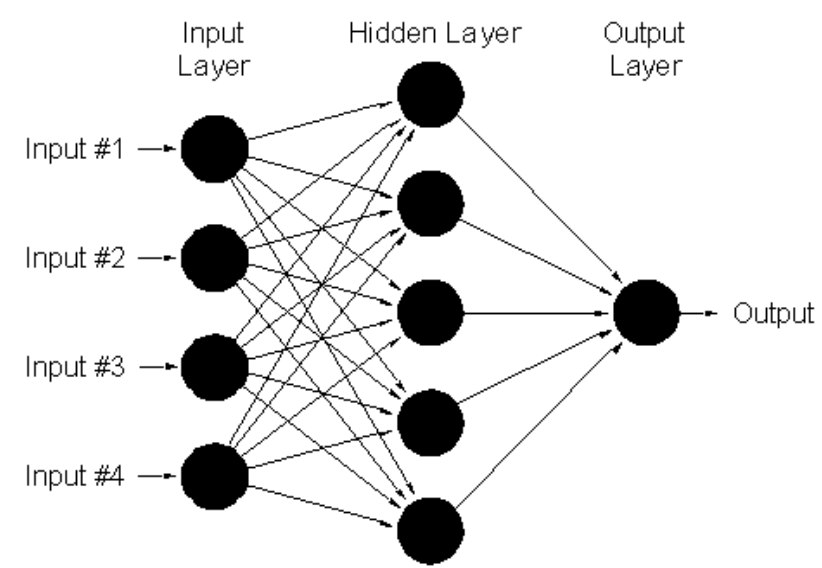

Figure 3. The structure of multi layer perceptrons

In this study a three layer feed forward ANN architecture was developed for predicting engine performance and output variables as like engine torque, input variables such as engine speed, exhaust gas temperature, biofuel mixture and coolant temperature in relation to input variables As shown in Figure 4, the used ANN structure for prediction of engine performance has hidden layers and the neuron numbers of the input output. Based on this analysis the optimal architecture of the ANN was constructed 4-15-1 NN architecture for torque representing the number of inputs, neurons in hidden layers and outputs respectively. Eventually After many iterations the optimal number of hidden nodes was adopted 15. The proposed ANN model is given in Figure 4. The learning algorithm used in the study is Levenberg Marquardt Algorithms activation function is logistic sigmoid (logsig) transfer functions and number of epochs is 30.000 .

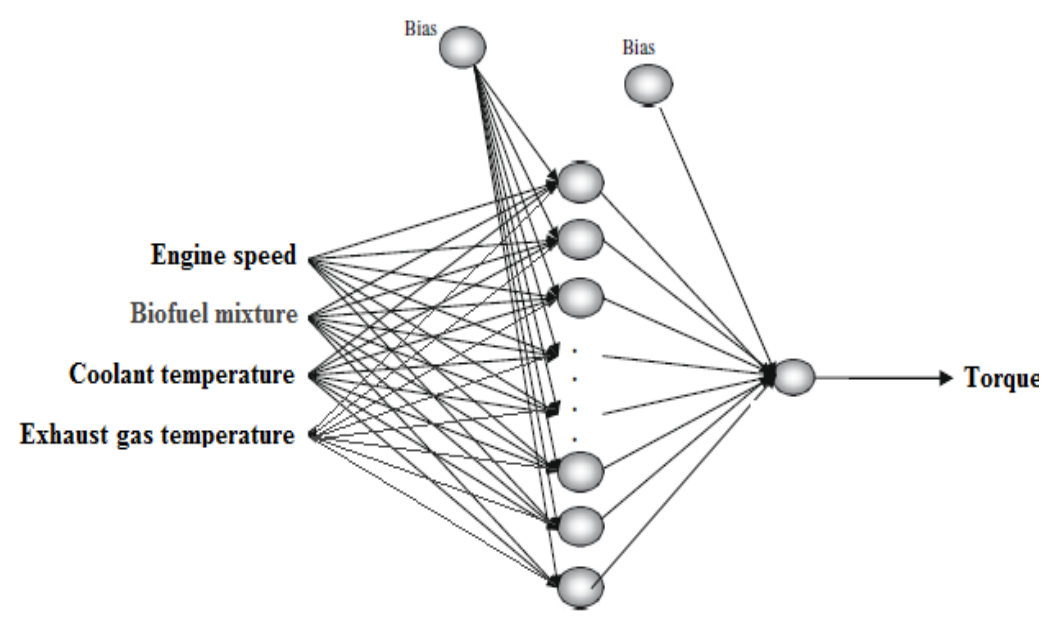

Input layer Hidden layer Output layer

Figure 4. The architecture of proposed NN model

\section{Artificial Neural Network model and Parameters}

The main idea of this study is the prediction of torque using ANN based on experimental results described above. Exhaust temperature, coolant temperature and engine speed have been used as input layer components, while the engine torque were used separately as output layer components of the ANNs. In the ANN model, the experimental data set includes 60 values of which 30 values were used for training the network and 11 values were selected randomly to test the performance of the trained network. In this study a computer program has been developed and performed under Matlab. The Levenberg Marquardt algorithm has been used in feed forward with one hidden layer. The input layer neurons 
receive information from the outside environment and transmit them to the neurons of the hidden layer without performing any calculation.

The hidden layer neurons then process the incoming information and extract useful features to reconstruct the mapping from the input space. The neighboring layers are fully interconnected by weights. Finally, the output layer neurons produce the network prediction to the outside world.The ANN model developed in this study is used to predict the torque based on the coolant temperature, exhaust temperature and engine speed. A total of 60 samples were used for training the network and other 11 (randomly) were used as a test set. Data set was normalized using a simple normalization method. The range of the samples and normalization values are given in Table 3.

Table 3. Values of input and output parameters

\begin{tabular}{ccc}
\hline Parameters & Value range & Normalized value \\
\hline ET $\left({ }^{\circ} \mathrm{C}\right)$ & $200-450$ & 200 \\
\hline $\mathrm{CT}\left({ }^{\circ} \mathrm{C}\right)$ & $30-80$ & 50 \\
\hline ES $(\mathrm{rmp})$ & $1500-400$ & 3500 \\
\hline BM $(\%)$ & $2-10$ & 6 \\
\hline $\mathrm{T}(\mathrm{Nm})$ & $35-95$ & 45 \\
\hline
\end{tabular}

\section{Analysis Results}

It was observed that a high prediction. Capability was achieved for both training and testing data sets of torque. Therefore the ANN appears to have a high generalization capability. Figure 5 has been shown the RMS error of the network with different learning parameters. Learning coefficient $(\eta)$, the momentum factor $(\alpha)$.

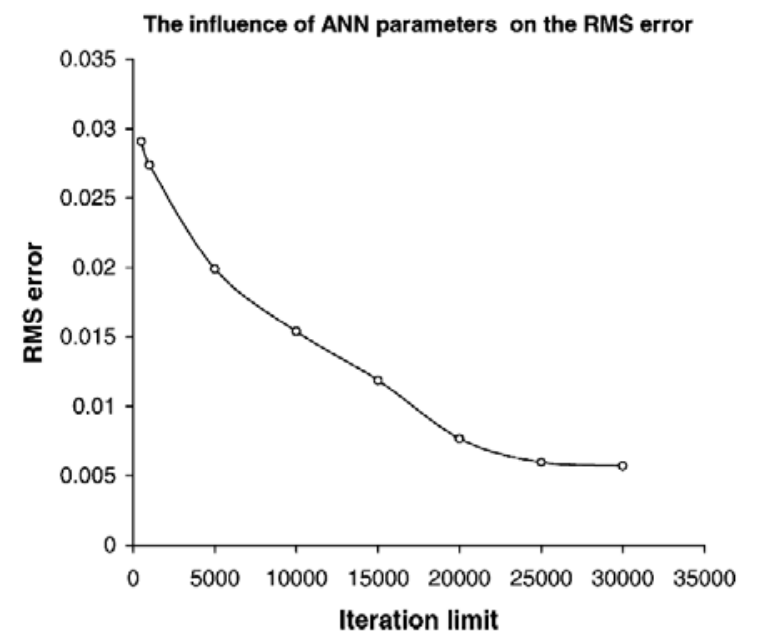

Figure 5. The influence of iteration limit on the RMS error $(\alpha: 0.8$, hidden neuron $: 12, \eta: 0.9$ )

Figure 5 showed that the ANN was capable of generalizing between engine speed of input variables and engine torque of output reasonably well. This study aims to present the closed form solution of torque based on the trained ANN parameters (weights and biases) as a exhaust temperature, coolant temperature and engine speed. Using weights and biases of trained ANN model engine torque can be given as follows The change in torque values depending on engine speed is presented in Figure 6.

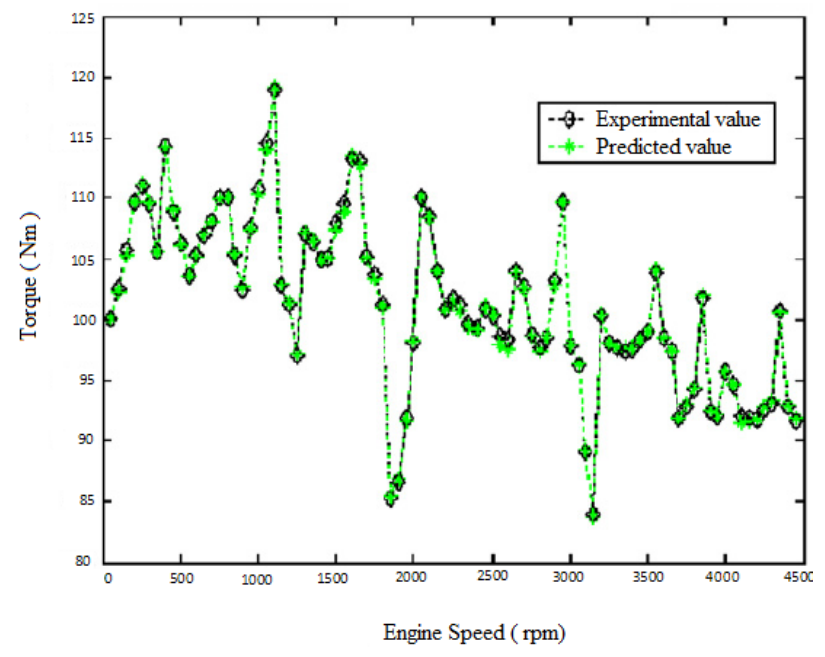

Figure 6. Variation of engine torque with engine speed

The contrast of prediction results and numerical experiment results of relationship between engine torque and coolant temperature are shown in Figure 7.

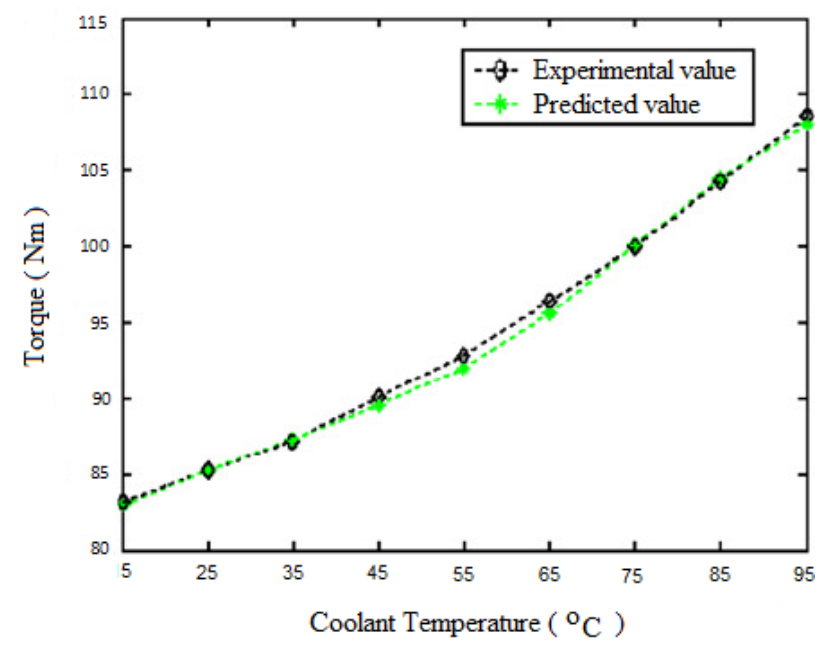

Figure 7. Relation between the engine torque with the coolant temperature

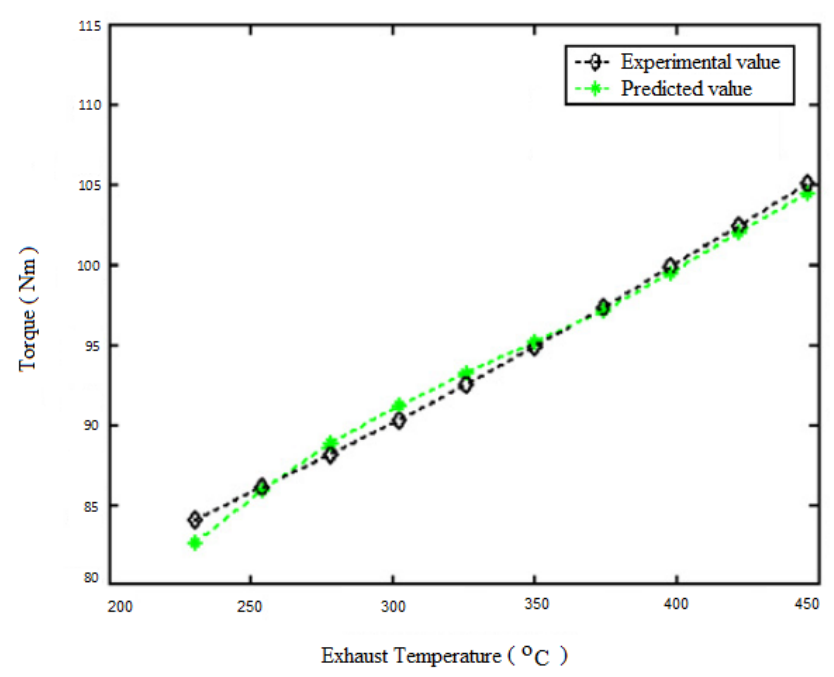

Figure 8. Variation of exhaust gas temperature with engine speed

The changes observed in exhaust temperature depending on engine speed are given in Figure 8. The exhaust temperature of ED fuel at $1000 \mathrm{rpm}$ was found to be $13 \%$ higher than SB fuel. The highest exhaust temperature values were observed at maximum engine 
speeds and ED fuel had the highest exhaust temperature compared to other fuels.The contrast of prediction results and numerical experiment results of relationship between engine torque and coolant temperature are shown in Figure 8.

The changes observed in the power values of the eurodiesel (ED) and canola biodiesel (CB) and soybean biodiesel (SB) fuel mixtures used in the diesel engine depending on engine speed are given in Fig. 9. The effective power characteristically increases depending on the increase of engine speed when the engine is run with eurodiesel fuel and biodiesel fuel. The highest engine power was obtained as $2300 \mathrm{rpm}$ in whole fuels. Engine power values obtained with ED fuel and SB and CB fuels were found to be close to each other at all engine speeds.

At higher engine speeds the differences among the power values obtained by using SB and CB fuels and ED fuel slightly increase depending on the increase of engine speed. The changes observed in engine torque depending on biofuel mixture are given in Fig. 9. As it can be seen the lowest biofuel mixture was observed when the engine was operated at approximately $1900 \mathrm{rpm}$ for all fuels. At this engine speed specific fuel consumption values of the engine when run with $\mathrm{BD}$ fuel were found to be $8 \%$ higher compared to ED fuel. Due to the low lower heating values of SB and CB fuels more fuel is injected to the engine in order to obtain a close amount of power provided by diesel fuel. This causes increases in biofuel mixture.

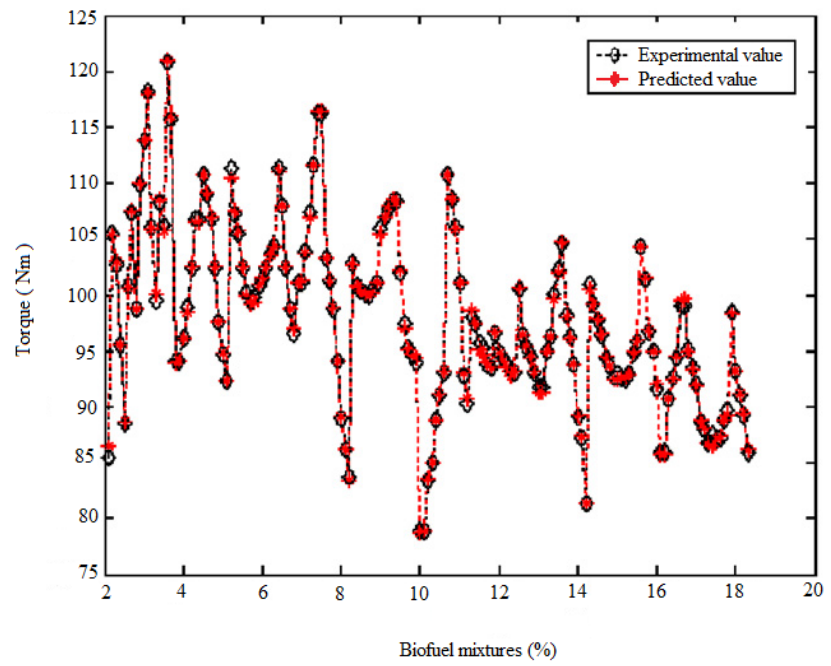

Figure 9. Variation of engine torque with biofuel mixtures

Also to assess the accuracy of ANN estimations, the regression curves are shown in Figure 10. ANN's estimation values of engine torque were assessed with regression analysis between estimated and experimental data. In order to prove ANN model estimation and regression $(\mathrm{R})$ were considered. The regression values were calculated as 0.98 for the engine torque respectively. After many iterations the optimal curve of $\mathrm{R}^{2}$ curve has been accepted in Figure 10.

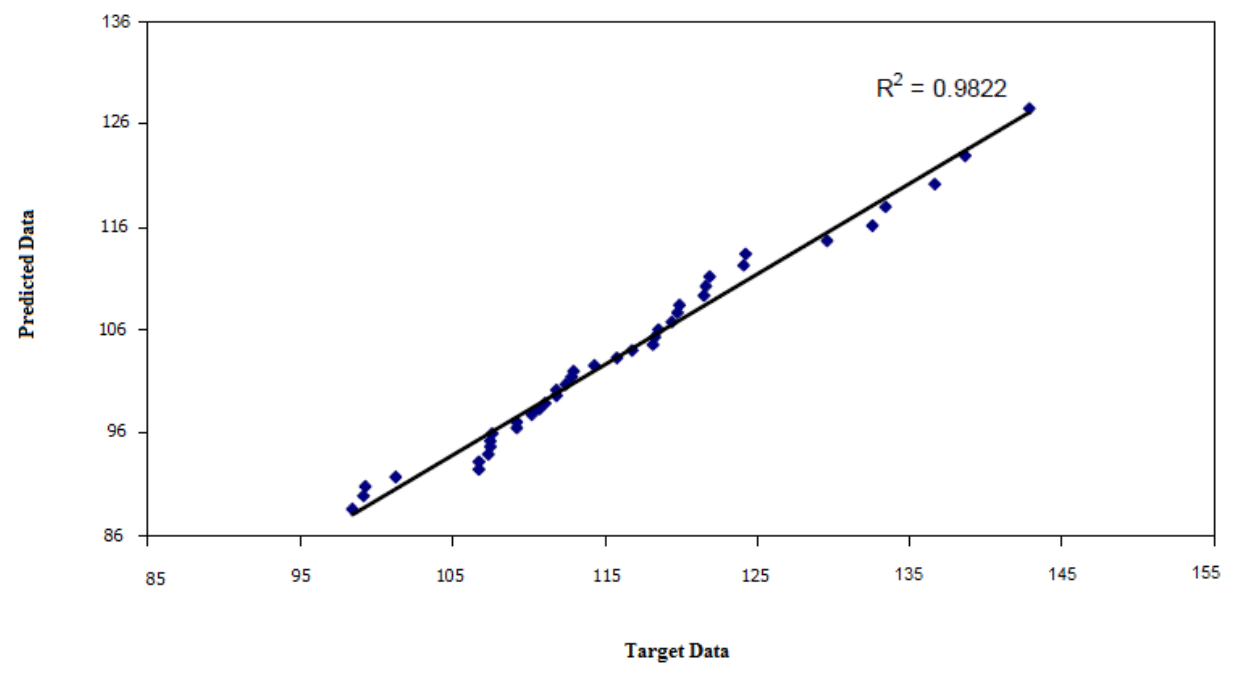

Figure 10. The predicted and the measured values of engine torque

One of the most important tasks in ANN studies is to determine the optimal network architecture which is related to the number of hidden layers and neurons in it. Usually the trial and error approach is used. In this study the best architecture of the network was obtained by trying different number of hidden layers and neurons. The trial started on hidden layer with five neurons and the performance of each network was checked by correlation coefficient (R). The goal is to maximize correlation coefficient to obtain a network with the best generalization. Many different network models were tried and their $\mathrm{R}$ values were calculated. The highest correlation coefficient for engine torque was obtained at a network.

\section{Conclusions}

In the present study diesel fuel and biodiesel fuels that were produced from diesel fuel mixed with canola oil methyl ester and soybean oil methyl ester were used respectively in a diesel engine without performing any modifications on the engine. The engine performance characteristics of these fuels were tested at full load and at different engine speeds. The engine performance change curves of each of the three fuels were obtained based on the acquired data and these curves were compared with each other. In this study Levenberg Marquardt ANN model with a 4-15-1 (number of input layer-hidden layer-output layer nodes) model was developed to predict and output variables engine torque and output variables exhaust heat temperature according to biofuel mixtures, engine speed and coolant temperature. 
The results showed that the training algorithm of Levenberg Marquardt was sufficient enough in predicting engine torque. It can be concluded that $\mathrm{R}$ values are very close to one for output parameters while the MSE error was 0.0007. In addition in the calculations for ANN estimation data set the correlation coefficient is 0.99. As a result the ANN results are very good, $\mathrm{R}$ values in this model are very close to one and have acceptable values while root mean square errors (RMSE) were found to be very low. It is showed that ANNs are a powerful tool for solving complicated engineering problems.

\section{Nomenclature}

$\begin{array}{ll}\text { ANN } & \text { Artificial Neural Network } \\ \text { LMA } & \text { Levenberg Marquardt algorithm } \\ \text { BM } & \text { Biofuel Mixture } \\ \text { CT } & \text { Coolant Temperature } \\ \text { MAPE } & \text { Mean Absolute Percentage Error } \\ \text { ES } & \text { Engine Speed } \\ \text { T } & \text { Torque } \\ \text { ET } & \text { Exhaust Temperature } \\ \text { RMS } & \text { Root Mean Square } \\ \text { BD } & \text { BioDiesel } \\ \text { ED } & \text { EuroDiesel } \\ \text { SB } & \text { Soybean Biodiesel } \\ \text { CB } & \text { Canola Biodiesel }\end{array}$

\section{References}

[1] Agarwal D, Kumar L, Agarwal AK. Performance evaluation of a vegetable oil fuelled compression ignition engine. Renewable Energy 2008; 33: 1147-1156.

[2] Balat $H$. Prospects of biofuels for a sustainable energy future: A critical assessment. Energy Educ Sci Technol Part A 2010; 24: 85111.

[3] Canakci M, Van Gerpen J. Comparison of engine performance and emissions for petroleum diesel fuel, yellow grease biodiesel and soybean oil biodiesel. Transact ASAE 2001; 46: 937-944.

[4] Demirbas A. Social, economic, environmental and policy aspects of biofuels. Energy Educ Sci Technol Part B 2010; 2: 75-109.

[5] Dincer K. Lower emission from biodiesel combustion. Energy Source Part A 2008; 30: 963-968.

[6] Kumar MS, Ramesh A, Nagalingam BA. Comparison of the different methods of using jatropha oil as fuel in a compression ignition engine. J Eng Gas Turb Power 2010; 132: 32801-32811.
[7] Aydogan H, Altun A.A, Ozcelik A. E. Performance analysis of a turbocharged diesel engine using biodiesel with back propagation artificial neural network. Energy Education Science and Technology Part A: Energy Science and Research 2011; 28: 459468.

[8] Banapurmatha NR, Tewaria PG, Hosmath RS. Performance and emission characteristics of a compression ignition engine operated on honge, jatropha and sesame oil methyl esters. Renew Energy 2008; 33: 1982-1988.

[9] Kalogirou SA. Artificial intelligence for the modeling and control of combustion processes: a review. Prog Energy Combus Sci 2003; 29: 515-566.

[10] Sayin C. Ertunc H. Hosoz M. Kilicaslan I. Canakci M. Performance and exhaust emissions of a gasoline engine using artificial neural network. Appl Therm Eng 2007; 27: 46-54.

[11] Golcu M. Sekmen Y. Erduranli P. Salman S. Artificial neural network based modeling of variable valve-timing in a spark ignition engine. Applied Energy 2005; 81: 187-197.

[12] Yuanwang D. Meilin Z. Dong X. Xiaobei C. An analysis for effect of cetane number on exhaust emissions from engine with the neural network. Fuel 2003; 81: 1963-1970.

[13] Ghobadian B. Rahimi H. Nikbakht AM. Najafi G. Yusaf T. Diesel engine performance and exhaust emission analysis using waste cooking biodiesel fuel with an artificial neural network. Renewable Energy 2009; 34: 976-982.

[14] Parlak A. Islamoglu Y. Yasar H. Egrisogut A. Application of artificial neural network to predict specific fuel consumption and exhaust temperature for a diesel engine. Appl Therm Eng 2006; 26 : 82-828.

[15] Hertz JA. Krogh AS. Palmer RG. Introduction to the Theory of Neural Computation, Addison-Wesley Publishing Company, Red Wood City, California, 1991.

[16] Kalogirou SA. Applications of artificial neural-networks for energy systems. Appl Energy 2000; 67: 17-35.

[17] Ozgur T, Tuccar G, Ozcanli M, Aydin K. Prediction of emissions of a diesel engine fueled with soybean biodiesel using artificial neural Networks. Energy Educ Sci Technol Part A 2011; 27: 301312.

[18] Eyercioglu O, Kanca E, Pala M, Ozbay E. Prediction of martensite and austenite start temperatures of the Fe-based shape memory alloys by artificial neural networks. J Mater Process Tech 2008; 200: 146-52.

[19] Togun N. K, Baysec S. Prediction of torque and specific fuel consumption of a gasoline engine by using artificial neural Networks Appl Energy 2010; 87: 349-355.

[20] Almeida LB. Multilayer Perceptrons, Handbook of Neural Computation, IOP Publishing Ltd. and Oxford University Press, 1997.

[21] Wang SW, Yu DL, Gomm JB, Page GF, Douglas SS. Adaptive neural network model based predictive control for air fuel ratio of SI engines. Eng Appl Artif Intel 2006; 19: 189-200. 